\title{
Responsible fashion SMEs in Hungary
}

\begin{abstract}
The fashion industry has been extensively attacked in recent years due to its severe environmental and social impact, to which large and multinational corporations have responded and come up with new initiatives. The aim of the current research is to seek answers to how small and medium-sized enterprises in the fashion industry having fewer resources are able to operate responsibly on the domestic market. After analysing three Hungarian and an Upper-Hungarian fashion industry SMEs with similar business profiles using the qualitative in-depth interview method, the research concluded that their strength lies mainly in their unique and sustainable products, and they consider opportunities for further development through partnerships and collaborations. The nature of the research is explorative and intends to provide a framework for a further analysis on sustainability and responsibility.
\end{abstract}

Keywords: corporate social responsibility, responsible SMEs, fashion industry, ethical values

\section{Introduction}

One of the leading and most complex industries, the fashion industry, has gradually developed an economic concept and approach (Jacometti 2019), creating dramatic concentration of demand and production. It also has a cultural, self-expressive, symbolic role, nevertheless, it is important to see that fashion items and products appear on the market as products of the economic sector, and globally speaking the textile industry is the second-largest polluter after the oil industry. There are serious social and

1 PhD student, Doctoral School of Entrepreneurship and Business, Budapest Business School University of Applied Sciences; e-mail: kortvesi.dorina@uni-bge.hu

DOI: http://dx.doi.org/10.31570/Prosp_2021_1_3 
environmental concerns due to the consumption of natural resources, mass production at low-level prices, therefore there is a strong need for the companies to re-think their strategies to operate in an ethical and environmentally friendly way (Claudio 2007). The textile industry is a broad term covering every sub-type of textiles from fibres, whether it is medical, technical, conventional, etc. The apparel, also known as the fashion industry, involves everything that is produced for wearing or covering a human body, embraces companies and activities such as designing, producing, and selling clothes, accessories, and footwear products from any type of materials (AbernathyWeil-Volpe 2006).

The European Union is an outstanding example where the fashion industry remains an SME- based industry and the second-largest exporter following China. It plays a diverse role in the European Union, providing job opportunities for 3 million people, and generating approximately 170 billion EUR yearly (European Commission, 2020). In alignment with global trends, EU consumption is characterised by a constant increase regarding the number of clothing products sold and the reduction in prices. In 2019, based on the calculations of the European Commission's Joint Research Centre, an EU citizen consumed an average of $26 \mathrm{~kg}$ of clothes (European Commission's Joint Research Centre, 2019), while less than half of the unused fashion items were collected for recycling, which process is at an early stage at a global scale as well. The EU launches several incentives to support the introduction and putting into practice of the actionbased circular economy.

The estimated number of fashion small and medium-sized enterprises on the Hungarian market is around 12,000 (European Commission, 2019). The average sales activity of the clothing and footwear industry is still dominated by large, international, and multinational companies. Hungarian consumers mostly buy clothing items from fast fashion brands that are essentially making the currently fashionable items available to all consumers with redesigned and transformed production and sales technologies, in an inexpensive, rapidly produced way (Euronews, 2019). The average expenditure on fashion items in Hungary is much lower than the average of the European Union (EUROSTAT, 2018). However, several initiatives were introduced to boost local fashion brands, and according to the (Euromonitor International , 2019), the most significant development was in the field of online shopping.

When it comes to the social and environmental aspects of the fashion industry, its impact is huge. The industry's ecological footprint exceeds the level of sustainability, pushing natural resource exploitation and land usage to its limits (Goworek 2011). Furthermore, the strengthening of the global middle class gradually increases the need for 
clothing. While the volume of the produced garments was 62 million tons in 2015, it is expected to jump to 102 million tons by 2050 (Rudenko 2018). The clothing and textile industry, with its mostly outsourced production lines and complex supply chains, is responsible for 1.7 billion tonnes of $\mathrm{CO} 2$ emission that in itself might be considered a serious contribution to global issues. The waste management systems are poorly constructed, globally $80 \%$ of clothing items produced go to waste incineration or landfills (The World Bank, 2019). After the agriculture sector, the textile industry is the second-largest water consuming industrial branch. One single cotton T-shirt requires 27000 litres of drinking water, which covers the needs of one person for 2.5 years, not mentioning the water-demand of the crop, cotton, and other raw materials used for garment production (Eco-Business, 2015).

On the other hand, social and human issues, lack of ethical production and working conditions, animal welfare, unfair wages, inequalities, forced and bonded (child) labour are only some of those global issues that widely occur in the apparel sector and seek urgent cooperation so that they will not remain unsolved (Perrini-Tencati 2010).

The COVID-19 pandemic and its consequences, such as the economic shutdown has hit the world unpredictably, meaning unprecedented challenges not only for the apparel industry but the entire economic and business sector. The black swan, which is frequently identified with a new era, has immediately become the symbol of the global pandemic (McMaster et al. 2020). The average market capitalization of apparel, fashion items dropped 40 percent between the period of January and March 24, 2020, which is a much steeper decline than what the overall stock market has experienced. Despite its unquestionable economic damage, several research studies identify the current situation as a fresh start and a shift to greener consumption, wakening up the industry and the consumers, bridging economic and environmental sustainability by creating innovative business models, emphasizing the need to strengthen the already existing partnerships and encouraging the brands to further develop their relational network involving the engagement of national stakeholders and creating sustainable supply chains (Fashion United, 2020).

\section{Theoretical framework}

The theoretical framework of the research relies on two not easily definable phenomena creating a coherent framework: corporate social responsibility and sustainability. 
Empirical literature frequently states that the willingness to do something good and pay back to the society for an organization is not a modern philosophy, but CSR is. It goes back to the $20^{\text {th }}$ century, originating in the United States, and it was institutionalised only in the late 1990'. Even nowadays, CSR has dozens of definitions, generally associated with the responsibility that businesses are expected to shoulder by the society (Dahlsrud 2006).

Definitions of CSR approach the issue from two main aspects, those that state that companies are obliged to make profit and maximize their financial interests within the framework of binding laws and rules accompanied by minimal ethical constraints (Friedman 1970) and those that demand a wider circle of responsibilities toward the society from businesses (Andrews 1973).

The traditional concept of corporate social responsibility (CSR) was introduced by (Carroll 1979). Not only did he distinguish four dimensions in the first edition of his book but he also described how to apply them. Although these four points remain the core of modern CSR, the corporate sector aspects have changed substantially with newly arisen issues due to the constantly changing context of the companies, new stakeholders, different national legislations, and globalisation (Pérez-Rodríguez del Bosque 2012):

- Economic responsibility is the most interconnected field with the three abovementioned ones, recognizing the corporate sector as the economic engine of the society.

- Legal responsibility, involving local and state regulations and binding laws.

- Ethical responsibility emphasizing the business firms' role not only to ensure employee welfare, creating fair working conditions (e. g., no discrimination based on gender, race, political view, etc.) but laying down principles for suppliers with fair trade standards.

- Philanthropic responsibility regarding vulnerable and needy people mostly in developing and underdeveloped countries, so companies invest their time, money, and resources to help them with (e. g., educational programs, donations) (Carroll 2016).

Kotler and Lee (2005) defined CSR as a business strategy, emphasising the businesses' voluntary contribution, theoretically differentiating it from the looking good approach and attempting to move it toward a doing well concept. According to their definition, 
CSR is a voluntary commitment to achieve social innovation and improve the given nation's wellbeing through business commitments.

The most important driver for the implementation of CSR by the business sector might be interconnected with the increasing need on the part of the society to get an insight into their activities, therefore companies had to push aside their financial profit-related motivation (Carroll-Shabana 2010), and nature, create a more transparent profile and convince their costumers about their ethically fair and environmentally conscious operation and practices. As a first step, businesses introduced internal audit systems, and reporting, which are also suitable measures to reveal their financial gains as a result of their CSR activities that might have several positive impacts, such as:

- attracting more consumers, increasing sales and profits,

- transparency and accountability attract more investors which reduces the companies' chance of being taken over,

- ensuring employee welfare that might result in a stable workforce on the long run, thus reducing turnover,

- good reputation and employee satisfaction may attract more potential labourforce; therefore, the company can choose the most qualified applicants (LörinczySroka 2015).

The original idea of sustainable development (SD) is relatively new, going back to 130 years. SD, just like the CSR, is defined in many ways in the literature, but the most frequently quoted definition is based on the Brundtland report (also known as Our Common Future report) dating from 1987 according to which "sustainable development is a development that meets the needs of the present without compromising the ability of the future generations to meet their own needs" (United Nations, 1987). The report stated that despite creating a holistic definition, it is expected that $\mathrm{SD}$ will remain a challenge to achieve for all the actors participating in the development processes.

SD introduced the Triple Bottom Line (TBL) concept for businesses based on the assumption set forth by John Elkington in 1994. He said that companies should align their operation with three bottom lines instead of focusing only on the profit and loss account. They should commit themselves to taking into consideration social and environmental concerns just as much as they do financial gains. It is also called the three Ps, and as its name implies the concept refers to a company's bottom line, which traditionally would be "profit and loss" for the company, but businesses must consider two more factors: people and the planet. The "people-account" reflects how socially 
responsible an organization is, while the "planet-account" measures environmentrelated consciousness (Elkington 1997).

The most comprehensive framework seeking international cooperation, involving NGOs, civil societies, governments, and individuals as well is provided by the United Nations Sustainable Development Goals, launched in 2015 within the 2030 Agenda for Sustainable Development. All its 17 goals with 169 targets were adopted by each UN member state to address complex social and environmental issues at both global and local levels (United Nations, 2018).

My research takes into consideration the nature of a small and medium-sized business since one of the main issues in discussing CSR implementation is that due to its nature and practices, CSR is mostly designed for large companies. Small and mediumsized enterprises play a significant role in the economy and have a great impact on society, yet there is little research and empirical findings on how SMEs can contribute in a profitable way to a sustainable future. SMEs are characterised by their multitasking nature, cash limited organisation, and are based on personal and informal relationships (Russo-Perrini 2010). Besides, they are actively managed by owners, and their economic growth is highly determined by their internal financial sources and decisionmaking processes.

To achieve sustainable development in the fashion industry, the EU has determined 3 directives (European Commission, 2014):

- increase the life cycle of clothing items by strengthening the position of slow fashion brands (mostly implemented by SMEs), enhancing the nature of service activities, more efficient recycling and repair practices, smart and customized fashion

- spreading clothing drives and recycling by circular-economy with extended producer responsibility

- withdrawing the consumers, by increasing consumer awareness and consciousness, developing the businesses' transparency and accountability with more efficient washing and drying instructions, more informative labels.

My research is based on the analysis of CSR, and sustainable development interconnections from a theoretical point of view. In practical terms, the paper attempts to uncover the current conditions and drivers of small and medium-sized companies (SMEs), and the circumstances under which they are able to operate responsibly and sustainably on the domestic market. 
The following research questions were formulated to gain relevant information and answers relating to the above-mentioned points:

1. Is sustainability reflected in the market operation and strategic decision making of domestic fashion small and medium-sized businesses?

2. How does the activity of the aware fashion SMEs relate to the sustainability of the economy/society/environment?

\section{Research methodology}

For the purposes of this research, I chose the qualitative methodology as my research method. Qualitative research is defined as market research and its concept is based on data gathering through open-ended and conversational-type communication to reveal answers to the question "why" (Grossoehme 2014). It provides several tools and forms to obtain data from the respondent, such as one-to-one interview, focus groups, case study research, etc. This study is based on a semi-structured in-depth interview with the founders of four small and medium-sized enterprises. The reason for finding and interviewing the heads of the given enterprises was based on (Zogjani-Raci 2015), stating that the leadership approach highly influences sustainable operation, ethical behaviour, and the level of expected responsibility in a given company, therefore it enabled me to directly analyse the brands' internal and external values, possible innovation processes from an organizational point of view and focus on intangible performances as well, taking into consideration their CSR related practices, ethical approaches, and the planned attempts regarding their future development. Three out of four interviews were conducted in Hungarian, while one in English. All four interviews were organised via Microsoft Teams. The timeframe of each interview was 15-20 minutes. The interview partners were able to answer all of the raised questions.

The semi-structured in-depth interview questions were the following: 


\section{Formulated interview questions}

\begin{tabular}{l|l}
\hline Q1 & What does a responsibly functioning company mean to you in the fashion industry? \\
Q2 & $\begin{array}{l}\text { What do you think are the indispensable/necessary „tools” or elements of being responsible } \\
\text { in the case of SMEs? Does it equal with sustainable fashion items as results on the market? }\end{array}$ \\
\hline Q3 & $\begin{array}{l}\text { In your opinion what are the current conditions /facilitators and barriers/ in Hungary for } \\
\text { small and medium size enterprises with respect to functioning responsibly? }\end{array}$ \\
\hline Q4 & $\begin{array}{l}\text { Have you drafted a social/sustainability and/or environmental annual report since the } \\
\text { foundation of the brand? If yes, has the report developed in the past years? - If no, how do } \\
\text { you measure the company's environmental impact on the local community? }\end{array}$ \\
\hline Q5 & $\begin{array}{l}\text { Have you drafted and/or adopted codes of ethics and/or codes of conduct? If yes, have the } \\
\text { codes developed in the past years? - If no, what kind of internal and ethical values do you } \\
\text { have within the company? }\end{array}$ \\
\hline Q6 & $\begin{array}{l}\text { Have you drafted a CSR annual report since the foundation of the brand? If yes, has the } \\
\text { report developed in the past years? - If no, how do you measure the company's social } \\
\text { impact on the local community? }\end{array}$ \\
\hline Q7 & $\begin{array}{l}\text { How do you see the future of your company? What steps, if any, would you implement at } \\
\text { the company to become more responsible? }\end{array}$ \\
\hline
\end{tabular}

The questions were structured to highlight the following points:

- Q1-Q3 questions relate to the SMEs' general approach to sustainability within the fashion industry, their operation, way of thinking, vision, and mission, creating a wider framework to discover how they see Hungarian market circumstances and conditions in which to run a responsible business.

- Q4-Q6 questions focus on the internal audit system of the given company, in terms of CSR, business ethics, and publication of sustainability reports, integration of sustainability measures in evaluation, environmental training, and resource efficiency. At that point, referring to the nature of SMEs based on the literature review, I was not expecting to find any reports, but how do they measure their environmental and social impact on the local society then?

- Q7 question highlights those steps that would be implemented in the SME business strategy to operate more sustainably.

\section{Research sample}

The research sample involved four small and medium-sized enterprises, three out of the four are located in Hungary (two in the capital, Budapest, and one in Debrecen), and one in Upper Hungary. These four companies were selected based on a prelimi- 
nary content analysis of their official websites to obtain background information. The research engine used the following keywords: sustainable fashion brands in Hungary, responsible Hungarian clothe shops, responsible fashion SME in Hungary, sustainability, and responsibility at Hungarian SMEs level, etc in the selection process. The chosen brands met with the officially acknowledged definition of small and medium-sized enterprises in terms of staff headcount and the entire turnover or balance sheet total (European Commission, 2020).

Regarding their daily operation, the four enterprises conduct diverse business activities.

PINKPONILO is an open fashion, design, and production studio, sewing self-made clothing from reused textile items since 2017. The company puts emphasis on awareness raising campaigns to inform the consumers about the harmful effects of the fashion industry. They promote new and innovative techniques, such as smart textile, and attempt to implement several measures to realise zero-waste production.

The capsule wardrobe definition makes unique the next enterprise, Zöld Gardrób (Green Wardrobe). Capsule collection is a widely used term in the fashion industry, while the capsule wardrobe specifically and personally designed for the given customers in a neat way, opening new opportunities to clean their closets with professional help. Zöld Gardrób not only applies this technique but collects items produced in an ethical and environmentally conscious way from its foreign partner enterprises to resell them in the Hungarian market. Furthermore, the enterprise provides a blog site for potential consumers to discuss responsibility-related hot topics.

The Mitter Sisters' profile can be divided into two important parts: the do-it-yourself workshop and education. The enterprise offers the opportunity for costumers to experience how much time, effort, material is used and invested into wearable items production by designing and making their own accessories from $100 \%$ sustainable leather materials. It raises the awareness to eco-friendly and conscious consumption, and also to fair working conditions, making the customer revalue the easily accessible and available fast fashion products.

The founder of Rename Fashion Design Studio currently works on transforming his business into a start-up in a long-term way. Currently, they design sales platforms, and the core of their activity is creating a circular economy with zero-waste management, and providing job opportunities for freelancer seamstresses, women and mothers who are able to work from home, ensuring them special conditions for subsistence.

Despite their various business activities, the research took into consideration the disclosed common points: 
- The founders of the enterprises are actively involved in the daily operation of the businesses; therefore, they directly mediate their sense of internal values and communicate them to the co-workers within the enterprise.

- The founders/co-founders/designers/co-workers have known each other for a long time, they have similar or the same educational background (e.g., having attended the same university), share a common way of thinking or approach toward sustainability and responsibility, thus they create a familiar and confidential atmosphere and environment.

- All of them are familiar with or are active members of the Fashion Revolution, which is a well-known international movement. The companies are taking part in this international voluntary partnership and are working steadily to achieve cultural, industry, and policy changes, sharing best practices and know-how, organizing conferences and design shows. Their commitment to and awareness of a responsibly run business are unquestionable.

\section{Research results:}

The in-depth interview is an effective tool to explore how close the answers get to the real views of the respondent, but its main concept and methodology is not designed to compare different answers. In this research, the interviewees - despite their separate business activities - showed significant similarities, therefore a SWOT analysis was applied to summarize the enterprises':

- strengths: what these enterprises are good at in terms of CSR, ethical values, and sustainability, how their performance can be differentiated from the less responsible competitors,

- weaknesses: especially focusing on their resources, systems, and procedures,

- opportunities: arise outside of the businesses, determining a future way of their development regarding their strategy, technology, raw material usage, etc., and

- threats: considering facts that might negatively affect the enterprises due to an outside situation. 
Table 1: SWOT analysis, summarizing the in-depth interviews, conducted with the 4 chosen SMEs in Hungary, 2020

\begin{tabular}{|c|c|}
\hline Strengths & Weaknesses \\
\hline $\begin{array}{l}\text { - appropriate educational background } \\
\text { - clear commitment } \\
\text { - environmental management system } \\
\text { eco-friendly production } \\
\text { - minimal or zero waste } \\
\text { - circular economy system } \\
\text { - consumer education } \\
\text { - unique products and services } \\
\text { - toyal consumers } \\
\text { transparency }\end{array}$ & $\begin{array}{l}\text { - limited financial resources } \\
\text { opportunities } \\
\text { - limited access to distribution channels } \\
\text { poor or lack of data-collecting tools } \\
\text { regarding their social impact } \\
\text { no code of ethics, reports, or any further } \\
\text { documents }\end{array}$ \\
\hline Opportunities & Threats \\
\hline $\begin{array}{l}\text { - tenders and scholarships provided by the } \\
\text { government, partnerships, universities, } \\
\text { NGOs } \\
\text { - networking } \\
\text { constantly increasing number of conscious } \\
\text { consumers }\end{array}$ & $\begin{array}{l}\text { lack of sustainably sensitive costumers } \\
\text { the presence of the large and multinational } \\
\text { companies }\end{array}$ \\
\hline
\end{tabular}

Source: Own compilation

I have uncovered several distinctive strengths among the analysed, responsibly run fashion SMEs.

All the four companies' founders acquired professional knowledge in terms of how to design and produce apparel items sustainably, therefore they are critically aware of their choice of material, suppliers, water and energy consumption, waste management. Their products are unique, not only compared to fast fashion items, but to each other as well. They define and advertise on the market a clear commitment they are proud of, enabling them to reach out to a wider circle of customers. They trust their vision and mission implementing educational panels into their core strategy to contribute to addressing social issues and be a member of a sustainable production chain and trade network. As one founder highlighted, it is impossible without voluntary activities, to distance herself as a leader from gaining financial profit and to invest to sustain a quality level living and at the same time give back to the society and the local community. 
Although according to two founders, the criteria of a responsibly run business cannot be generalized but one might think of indispensable elements such as ethical manufacturing, strategically planning the lifecycle and the durability of the produced items, eco-friendly approaches, etc.

PINKPONILO, for example, functions as an open studio manifesting not only their openness to attempting to attract more consumers but ensuring transparency through making their internal production procedures visible and tangible. Two enterprises use an international environmental management system, namely Choose, a Norwegian company providing impactful climate solution services, calculating the given business's ecological footprint, and making available digital tools to neutralise it.

The weaknesses of the studied enterprises are mostly related to the nature of small and medium-sized enterprises. They have limited financial resources that results in limited opportunities for investments, salaries, and expansion. However, they have access to all social media platforms to conduct proper communication from the brands' point of view. Still their competencies and chances are less significant compared to large or multinational companies. They also regularly face the limitation of accessing distribution channels. Furthermore, data-collecting tools - especially from an environmental perspective - might be crucial to forecast demand, helping with production plans, and determining the suitable supply chains and modes of transports. All four companies stated that they do not have an internal audit system as it was expectable in the case of SME analysis. They have registered records relating to working hours, the durability of production, number of workshop participants but they are unable to measure their social impact. Furthermore, they do not have any ethics or sustainability related documentation they would draw up regularly. One of the founders has social impact measurement strategic plans, by gaining feedback from the customers directly through short and easily fillable questionnaires and surveys evaluating their satisfaction with the provided services and products.

The Hungarian market assessment was positive for all four enterprises. They highlighted several opportunities, such as financial grants and packages, initiatives, ongoing training to develop their businesses. The European Union provides a framework, the so-called "Support report mapping sustainable fashion opportunities for SMEs" (European Commission, 2019) listing all the initiatives that SMEs can take part in to achieve sustainable improvements, dividing the available initiatives for companies with different business profiles by grouping their activities. Information and best practices sharing are relatively well-developed and slow fashion brands are characterised by a cohesive attitude. Two founders have trade-off partners meaning when they cannot 
take further orders instead of rejecting them, they recommend their partner enterprises. As it was discussed in the literature review, there is a slowly increasing need for sustainable products, therefore the number of conscious consumers is growing as well generating a higher demand for responsibly manufactured apparel items. Although the four SMEs have bright ideas and solutions for further development in the future, such as educating at different levels, bringing innovation closer to the industry, cooperating at local, regional, national, even international level, creating a circular economy, and offering recycling alternatives, currently, the Hungarian market is dominated by international brands and large companies, mainstream fashion is still dominated by fast fashion brands.

\section{Conclusion}

As a general conclusion, I can say that future development directions and opportunities, such as consumer satisfaction, brand reputation, additional financial gains, and liquidity are some of the drivers that might be attractive for the SME sector to be responsible and implement CSR and business ethics management.

The literature implied that it is not expectable to analyse SMEs based on their internal audit or reporting system due to their nature and size, they rather have internal values, visions and missions that determine their operation on the market. Answering the first research question, sustainability is reflected in the analysed fashion SMEs' decision-making processes and market strategies, paying attention to the social matters and environmental impact they might have and this takes place voluntarily. The same situation was proven true for all four investigated companies. They operate ethically and sustainably because it is their commitment, aligned with their mission and vision having been determined even before their establishment. The founders and therefore the co-workers are familiar with the original concept of CSR, but internal measurement systems are non-existent. Instead, they have strong internal and ethical values and constantly work on bringing change into the society and take a stand in debated issues such as inequalities, protectionism, fairness, lack of transparency, and accountability. They consider their market position strong due to their responsible commitment, while their weaknesses might originate from their nature as small and mediumsized enterprises.

Speaking of the second research question, the interviews showed that the core of being a responsibly functioning SME in the fashion industry is based on several pillars: adequate consumer education, partnerships through the sector at different levels, 
building various flourishing networks, creating platforms for best practices, inspiring and innovative ideas, and solutions.

Summarizing the literature review and the research findings to answer the research questions, I can say that sustainability is reflected in the four analysed enterprises' market operation and strategic decisions as small and medium-sized businesses, their activities strongly relate to not only producing slow fashion items but also to address economic, social and environmental issues from a sustainable point of view, which also differentiates them from traditionally functioning enterprises on the domestic market.

\section{References}

Abernathy, F. - Weil, D. - Volpe, A. (2006). The future of the apparel and textile industries: Prospects and choices for public and private actors. Environment and Planning, 38(12), 2207-2232.

Andrews, K. (1973). Can the best corporations be made moral? Harvard Business Review, 57-64.

Carroll, A. B. (1979). A three-dimensional conceptual model of social performance. The Academy of Management Review, 4(4), 497-505. doi: https://doi.org/10.2307/257850

Carroll, A. B. (2016). Carroll's pyramid of CSR: Taking another look. International Journal of Corporate Social Responsibility, 1(3). doi: https://doi.org/10.1186/s40991016-0004-6

Carroll, B. A. - Shabana, K. M. (2010). The business case for corporate social responsibility: A review of concepts, research and practice. International Journal of Management Reviews, 12(1), 85-105. doi: https://doi.org/10.1111/j.1468-2370.2009.00275.x

Claudio, L. (2007). Waste couture: Environmental impact of the clothing industry. Environmental Helath Perspectives, 115(9), 448-454. doi: https://doi.org/10.1289/ ehp.115-a449

Dahlsrud, A. (2006). How corporate social responsibility is defined: An analysis of 37 definitions. Corporate Social Responsibility and Environmental Management, 1-13. doi: $\underline{\text { https://doi.org/10.1002/csr.132 }}$

Eco-Business. (2015. ). Eco-Business. Forrás: How much water is in your shirt? (Sept. 17.) https://www.eco-business.com/news/how-much-water-is-in-your-shirt/ Elkington, J. (1997). Cannibals with Forks - Triple Bottom Line of 21st Century Business. Stoney Creek: CT: Newy Society Publishers. 
Euromonitor International (2019). Apparel and Footwear in Hungary. London: Euromonitor International.

Euronews (2019). Euronews. (February 15). Forrás: Hungarian sustainbale designer labels to know: https://www.euronews.com/living/2019/02/15/hungarian-sustainable-designer-labels-to-know

European Commission (2014). Action Plan for Fashion and High-end Industries. Brussels: European Commission.

European Commission (2019). 2019 SBA Fact Sheet Hungary. Brussels: European Commission.

European Commission (2019). Support Report Mapping Sustainable Fashion Opportunities for SMES. Brussels, Belgium.

European Commission (2020). European Commission (11. 11.) Forrás: Internal Market, Industry, Entrepreneurship and SMEs: https://ec.europa.eu/growth/smes/smedefinition en

European Commission (2020). European Commission (01. 12). Forrás: Internal Market, Industry, Entrepreneurship and SMEs: https://ec.europa.eu/growth/sectors/ fashion/textiles-clothing en

European Commission's Joint Research Centre (2019). European Environment Agency. (11. 19.) Forrás: Textiles in Europe’s circular economy: https://www.eea.europa. eu/themes/waste/resource-efficiency/textiles-in-europe-s-circular-economy

EUROSTAT (2018). EUROSTAT. (February 27.) Forrás: A closer look at clothes and footwear in the EU: https://ec.europa.eu/eurostat/web/products-eurostat-news/-/ EDN-20180227-1

Fashion United (2020). Fashion United (July 07). Forrás: Impact of Covid-19 / Coronavirus on fashion industry: $\underline{\text { https://fashionunited.com/specials/coronavirus-apparel- }}$ industry

Friedman, M. (1970). The social responsibility of business is to increase its profits. The New York Times Magazine, 122-126.

Goworek, H. (2011). Social and environmental sustainability in the clothing industry: A case study of a fair trade retailer. Social Responsibility Journal, 7(1), 74-86. doi: https://doi.org/10.1108/17471111111114558

Grossoehme, D. (2014). Overview of qualitative research. Journal of Health Care Chaplaincy, 20(3), 109-122. doi: https://doi.org/10.1080/08854726.2014.925660

Jacometti, V. (2019). Circular economy and waste in the fashion industry. Laws, 8(4), 27-40. doi: https://doi.org/10.3390/laws8040027 
Kotler, P. -Lee, N. (2005). Corporate Social Responsibility: Doin the Most Good for Your Company and Your Cause. New Yersey: John Wiley and Sons, Inc.

Lörinczy, M. - Sroka, W. (2015). The perception of ethics in business: Analysis of research results. Procedia Economics and Finance, 34, 156-163. doi: https://doi. org/10.1016/S2212-5671(15)01614-7

McMaster, M. - Belanda, X. B. - Nettleton, C. - Tom, C. (2020). Risk management: Rethinking fashion supply chain management for multinational corporations in light of the COVID-19 outbreak. Journal of Risk and Financial Management, 13(8), 173-189. doi: https://doi.org/10.3390/jrfm13080173

Pérez, A. - Rodríguez del Bosque, I. (2012). The role of csr in the corporate identity of banking service providers. Journal of Business Ethics, 108, 145-166. doi: https://doi. org/10.1007/s10551-011-1067-7

Perrini, F. - Tencati, A. (2010). Sustainability and stakeholder management. The need for new corporate performance evaluation and reporting system. Journal of Fashion Marketing and Management, 300-311. doi: https://doi.org/10.1002/bse.538

Rudenko, O. (2018). Share clothe. Forrás: The 2018 Apparel Industry Overproduction Report and Infographic: https://sharecloth.com/blog/reports/apparel-overproduc$\underline{\text { tion }}$

Russo, A. -Perrini, F. (2010). Investigating stakeholder theory and social capital: CSR in large firms and SMEs. Journal of Business Ethics, 91, 207-221. doi: https:/doi. org/10.1007/s10551-009-0079-Z

The World Bank (2019). The World Bank. Forrás: How Much Do Our Wardrobes Cost to the Environment? https://www.worldbank.org/en/news/feature/2019/09/23/costo-moda-medio-ambiente

United Nations (1987). Report of the World Commission on Environment and Development. New York: United Nations.

United Nations (2018). United Nations. Forrás: Sustainable Development Goals: https://sdgs.un.org/goals

Zogjani, J. - Raci, S. (2015). The role of leadership in achieving sustainable organizational change and the main approaches of leadership during organizational change. Academic Journal of Interdisciplinary Studies, 4(3), 65-70. doi: https://doi. org/10.36941/ajis 